\title{
Toward vicarious calibration of microwave remote-sensing satellites in arid environments
}

Article

Accepted Version

Rüdiger, C., Walker, J. P., Kerr, Y. H., Kim, E. J., Hacker, J. M., Gurney, R. J., Barrett, D. and Le Marshall, J. (2013) Toward vicarious calibration of microwave remote-sensing satellites in arid environments. IEEE Transactions on Geoscience and Remote Sensing, 52 (3). pp. 1749-1760. ISSN 0196-2892 doi: https://doi.org/10.1109/TGRS.2013.2254121 Available at https://centaur.reading.ac.uk/33421/

It is advisable to refer to the publisher's version if you intend to cite from the work. See Guidance on citing.

To link to this article DOI: http://dx.doi.org/10.1109/TGRS.2013.2254121

Publisher: IEEE Geoscience and Remote Sensing Society

Publisher statement: (c) 2013 IEEE. Personal use of this material is permitted. Permission from IEEE must be obtained for all other users, including reprinting/ republishing this material for advertising or promotional purposes, creating new collective works for resale or redistribution to servers or lists, or reuse of any copyrighted components of this work in other works.

All outputs in CentAUR are protected by Intellectual Property Rights law, including copyright law. Copyright and IPR is retained by the creators or other copyright holders. Terms and conditions for use of this material are defined in the End User Agreement. 


\section{www.reading.ac.uk/centaur}

\section{CentAUR}

Central Archive at the University of Reading

Reading's research outputs online 


\title{
Toward Vicarious Calibration of Microwave Remote-Sensing Satellites in Arid Environments
}

\author{
Christoph Rüdiger, Member, IEEE, Jeffrey P. Walker, Yann H. Kerr, Fellow, IEEE, \\ Edward J. Kim, Senior Member, IEEE, Jörg M. Hacker, Robert J. Gurney, \\ Damian Barrett, and John Le Marshall
}

\begin{abstract}
The Soil Moisture and Ocean Salinity (SMOS) satellite marks the commencement of dedicated global surface soil moisture missions, and the first mission to make passive microwave observations at L-band. On-orbit calibration is an essential part of the instrument calibration strategy, but on-board beam-filling targets are not practical for such large apertures. Therefore, areas to serve as vicarious calibration targets need to be identified. Such sites can only be identified through field experiments including both in situ and airborne measurements. For this purpose, two field experiments were performed in central Australia. Three areas are studied as follows: 1) Lake Eyre, a typically dry salt lake; 2) Wirrangula Hill, with sparse vegetation and a dense cover of surface rock; and 3) Simpson Desert, characterized by dry sand dunes. Of those sites, only Wirrangula Hill and the Simpson Desert are found to be potentially suitable targets, as they have a spatial variation in brightness temperatures of $<4 \mathrm{~K}$ under normal conditions. However, some limitations are observed for the Simpson Desert, where a bias of $15 \mathrm{~K}$ in vertical and $20 \mathrm{~K}$ in horizontal polarization exists between model predictions and observations, suggesting a lack of understanding of the underlying physics in this environment. Subsequent comparison with model predictions indicates a SMOS bias of $5 \mathrm{~K}$ in vertical and $11 \mathrm{~K}$ in horizontal polarization, and an unbiased root mean square difference of $10 \mathrm{~K}$ in both polarizations for Wirrangula Hill. Most importantly, the SMOS observations show that the brightness temperature evolution is dominated by regular seasonal patterns and that precipitation events have only little impact.
\end{abstract}

Index Terms-Calibration, environmental monitoring, passive microwave remote sensing, soil moisture.

Manuscript received May 1, 2011; revised September 23, 2012; accepted February 14, 2013. This work was supported by the Australian Research Council Discovery Project under Grant DP0879212.

C. Rüdiger and J. P. Walker were with the Department of Civil and Environmental Engineering, The University of Melbourne, Parkville 3010, Australia. They are now with the Department of Civil Engineering, Monash University, Clayton 3800, Australia (e-mail: chris.rudiger@monash.edu; jeff.walker@monash.edu).

Y. H. Kerr is with Centre d'Etudes Spatiales de la Biosphère, CESBIO, Toulouse 31401, France (e-mail: yann.kerr@cesbio.cnes.fr).

E. J. Kim is with the NASA Goddard Space Flight Center, Greenbelt, MD 20771 USA (e-mail: ed.kim@nasa.gov).

J. M. Hacker is with Airborne Research Australia, Flinders University, Adelaide 5106, Australia (e-mail: jorg@airborneresearch.com.au).

R. Gurney is with NERC Environmental Systems Science Centre, University of Reading, Reading RG6 6UR, U.K. (e-mail: rjg@mail.nerc-essc.ac.uk).

D. Barrett is with Commonwealth Scientific and Industrial Research Organization, Land and Water, Canberra 2601, Australia (e-mail: d.barrett@smi.uq.edu.au).

J. Le Marshall is with the Bureau of Meteorology Research Center, Bureau of Meteorology, Melbourne 3000, Australia (e-mail: j.lemarshall@bom.gov.au).

Color versions of one or more of the figures in this paper are available online at http://ieeexplore.ieee.org.

Digital Object Identifier 10.1109/TGRS.2013.2254121

\section{INTRODUCTION}

$\mathbf{T}$ HE European Space Agency-led Soil Moisture and Ocean Salinity (SMOS) mission [1], [2] was successfully launched on November 2, 2009. This satellite is designed to provide global L-band brightness temperature observations at a resolution of $\sim 40 \mathrm{~km}$ with an equatorial repeat overpass approximately every three days. Unlike other passive microwave remote-sensing satellites that are used to give soil moisture information from observations at nonideal wavelengths, such as the Scanning Multichannel Microwave Radiometer [3], the Advanced Microwave Scanning Radiometer for the Earth Observing System (AMSR-E) [4], or WindSat [5], SMOS is dedicated to soil moisture observation from the space at an optimal wavelength (L-band; $1.413 \mathrm{GHz}$ ). In addition, to circumvent the passive microwave remote-sensing requirement for a single large aperture dish antenna, SMOS uses a new satellite design that is similar to the synthetic aperture techniques used in radio astronomy (such as the Very Larger Array in New Mexico, USA), which synthesize a large antenna size using a large number of individual sensors arranged in a specific pattern.

One advantage of this technique is that it provides observations for a range of incidence angles for each pixel in the swath. However, a total of 69 individual receivers are used to derive a single observation means that the knowledge of the in-flight characteristics of each receiver is critically important for the technique to work. Therefore, a postlaunch commissioning phase of several months is required for validation and calibration purposes, and vicarious calibration targets play a critical role in this process. Vicarious calibration is also shown to be important following the launch of AMSR-E (which used a traditional microwave antenna), where data distribution is delayed by several months because of physical temperature drifts (caused by solar heating and the subsequent cooling in the Earth's shadow) of the on-board hot calibration target resulting in large errors [6]. This problem was eventually overcome by using thermal information of the Earth's surface from other microwave radiometers in orbit at roughly the same time [7]. Although SMOS similarly relies on cold sky and on-board reference noise injector radiometers for its on-orbit calibrations, it is explicitly stated in the algorithm theoretical basis document that the ultimate calibration can only be obtained using vicarious methods [8]. To achieve this, surface targets with stable, or at least predictable, radiometric conditions are required. 
Because of the difficulties with on-board calibration targets, a number of studies have been undertaken to identify vicarious calibration targets for passive microwave radiometers. Such targets may include the deep sky $(\sim 2.7 \mathrm{~K}$; [9]), Antarctica ( $190 \mathrm{~K}$ at C-band; [10]), stable parts of the ocean $(\sim 115 \mathrm{~K}$; [11]), tropical forests $(\sim 290 \mathrm{~K}$; [12]), and arid regions (assumed to be temporally variable but spatially stable), providing a range of on-orbit calibration targets from cold to hot. This vicarious calibration approach requires targets with spatially stable conditions of known or predictable surface emissions. Along with the ground-based calibration targets, SMOS makes a deep space observation during one orbit every two weeks for its cold reference. As an example of the low-temperature ground calibration targets, Dome- $\mathrm{C}$ in the Antarctic is shown to have an almost constant brightness temperature of $\sim 190 \mathrm{~K}$ at L-Band [10] at $42^{\circ}$ incidence angle. Similarly, the Amazonian forest is found to have only little variation at C-band with a brightness temperature of $290 \mathrm{~K}$ [12], suggesting that dense tropical forests might also be a suitable calibration target at L-band provided we can assume a total opacity of the canopy. Other calibration targets include ice-free sea surfaces, for which the salinity effect is minimal and their physical temperature is well known and very stable with low or welldescribed wind conditions. Finally, a further warm load calibration target, the Taklamakan Desert in China, is suggested as a potential candidate; however, radio-frequency interferences in China are significant, introducing a large uncertainty on the space-borne measurements [13]. Therefore, other desert calibration sites must be identified.

This paper uses prelaunch airborne field campaign data from the SMOS Arid Zone Experiments in Australia, and SMOS brightness temperature observations along with European Centre for Medium Range Weather Forecasting (ECMWF) Reanalysis (ERA-Interim) land surface model predictions. The field campaigns were undertaken in November 2008 and August 2009 to test the suitability of three potential on-orbit warm calibration targets for passive microwave satellites at Lband. The sites tested were chosen for their assumed spatial homogeneity in terms of surface conditions (soil moisture and temperature, vegetation, soil type, and so on), and therefore their expected homogeneous microwave response. The extent of each study site is $\sim 50 \mathrm{~km} \times 50 \mathrm{~km}$, approximately the size of a SMOS footprint at $3 \mathrm{~dB}$.

\section{Study Sites And DATA Sources}

In this paper, the three sites tested for their microwave response reside within the Australian arid zone (Fig. 1), which is typically subjected to $<60-\mathrm{mm}$ annual precipitation [14], and therefore display little short-term temporal and spatial variation from the climatological mean in terms of surface soil moisture and temperature. In addition, they each contain only sparse vegetation cover. These environmental conditions are expected to make those sites suitable warm calibration targets for space-borne microwave sensors. Two different types of data were collected for each site 1) airborne and 2) in situ. The airborne data consist of brightness temperatures

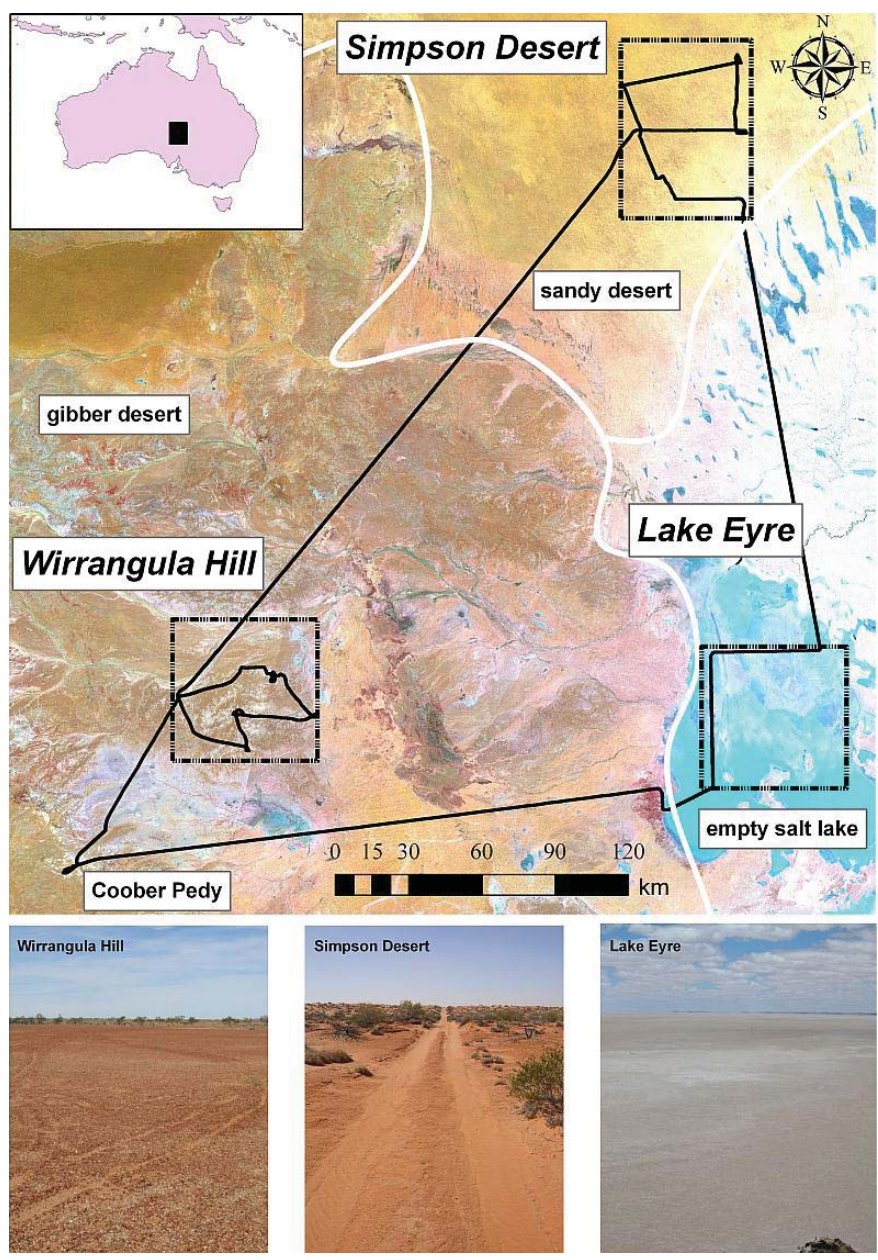

Fig. 1. Location of the study area within Australia (inset), the focus sites (dashed-line squares), and reconnaissance flight track (solid black line), overlain on a Landsat image. The dominant surface conditions are indicated and the corresponding regions are separated by the white lines along with example images of the ground views (below).

obtained with the airborne Polarimetric L-band Multibeam Radiometer (PLMR; observation frequency of $1.413 \mathrm{GHz}$ ) at a resolution of $1 \mathrm{~km}$. Coincident broadband thermal infrared (TIR) measurements were made at the same resolution, with data sets fully covering all three study areas. The in situ data include soil profile temperatures and soil moisture content from fixed base stations and soil cores, and spatially distributed measurements of surface soil moisture variation using the Hydraprobe Data Acquisition System (HDAS) developed for collecting point measurements of soil moisture and ancillary data across local scales [15]. The study sites and the instrumentation used are described in detail in the following sections.

The low-resolution flights cover a complete SMOS footprint of $\sim 50 \mathrm{~km} \times 50 \mathrm{~km}$ at 1-km resolution supplemented by highresolution flights in localized areas along predefined flight paths at 50-m resolution (Fig. 1 for the general overview of the high-resolution flight paths). An overview of the flight dates and data collected is presented in Table I. The flights were timed such that regional coverage would be centered on the 6 A.M. SMOS overpass time (with the observation window of the flights generally ranging from 4 to 8 A.M.). 
This article has been accepted for inclusion in a future issue of this journal. Content is final as presented, with the exception of pagination.

TABLE I

Overview of Dates and Data Collected for the Five Flights. The Last Column Shows the Spatial Variability of the Low-Resolution $(1 \mathrm{~km})$ PLMR Data

\begin{tabular}{|l|l|l|l|l|}
\hline Site & Surface Type & Measurements-Airborne/Ground based & Flight Dates & Tb Standard Deviation (K) \\
\hline Reconnaissance & $\begin{array}{l}\text { Dry salt lake (LE) } \\
\text { Sandy desert (SD) } \\
\text { Gibber (WH) }\end{array}$ & $\begin{array}{l}\text { PLMR, thermal IR/thermal IR, profile soil } \\
\text { moisture, and temperature }\end{array}$ & November 9, 2008 & $\begin{array}{l}\text { Only high resolution: 12.6/10.4 (LE } \\
- \text { wet/dry) 5.2 (WH) 10.1 (SD) }\end{array}$ \\
\hline Lake Eyre & Dry salt lake & $\begin{array}{l}\text { PLMR, thermal IR/profile soil temperature, } \\
\text { and surface soil moisture }\end{array}$ & November 10, 2008 & $\begin{array}{l}\text { High resolution (wet/dry): 16.1/15.6 } \\
\text { Low resolution (wet/dry): } 13.2 / 19.6\end{array}$ \\
\hline Simpson Desert & Sandy desert & $\begin{array}{l}\text { PLMR, thermal IR, photography/thermal IR, } \\
\text { profile soil moisture and temperature, surface } \\
\text { soil moisture, and deep core samples }\end{array}$ & November 15, 2008 & $\begin{array}{l}\text { High resolution (wet/dry): 8.6/9.8 } \\
\text { Low resolution (wet/dry): 9.5/8.7 }\end{array}$ \\
\hline & & & August 11, 2009 & Low resolution: 1.5 \\
\hline $\begin{array}{l}\text { Wirrangula } \\
\text { Hill }\end{array}$ & Gibber & & November 12, 2008 & $\begin{array}{l}\text { High resolution: 4.1 } \\
\text { Low resolution: } 3.3\end{array}$ \\
\hline & & & August 12, 2009 & Low resolution: 3.5 \\
\hline
\end{tabular}

An exception to this was a reconnaissance flight, undertaken to obtain information about the spatial conditions across the field sites for the identification of focus areas to be used later for the local ground-sampling activities. This flight took place in the afternoon because of logistical reasons and covered only the high-resolution area across the three focus sites (Fig. 1), conducted once only at the start of the first campaign (November 9, 2008). The coverage included only singletransect high-resolution $(50 \mathrm{~m})$ flights over ground accessible areas of the three study sites, with the intent of characterizing spatial anomalies in the data before the intensive ground sampling.

The study sites have contrasting surface conditions typical of the Australian arid zone and include: 1) Lake Eyre, a typically dry salt lake that is characterized by a predominantly moist sandy material under a layer of salt crust; 2) Wirrangula Hill, located within a large cattle station to the northeast of Coober Pedy and characterized by a dense cover of surface rock with almost no vegetation; and 3) the Simpson Desert, characterized by typically very dry sand dunes oriented in a north-south direction with low levels of vegetation.

It is important to note that a rain event had passed through the northern part of Wirrangula Hill and the Simpson Desert a few days before the field campaign in November 2008. In addition, another significant storm front passed through the northern part of the Simpson Desert in the early hours of the morning of November 15, 2008 (the night that the flight took place). In contrast, no or only very little rain fell over any of the three sites throughout the nine-month period before the second campaign, resulting in the typical extremely dry conditions also expected in the first campaign.

\section{A. Lake Eyre}

Lake Eyre is a typically dry salt lake located between $27.8^{\circ}$ $29.1^{\circ} \mathrm{S}$ and $136.7^{\circ}-137.8^{\circ} \mathrm{E}$ in the northern part of South Australia (Fig. 1). It includes the lowest inland elevation in Australia at $15 \mathrm{~m}$ below sea level. The Lake Eyre drainage basin totals an area of 1.1 million $\mathrm{km}^{2}$ with floods of varying quantities occurring irregularly every $3-5$ years (in the recent past, this lake had been flooded in three successive years since 2009, reaching a water depth of $1.5 \mathrm{~m}$ in August 2009). Those floods generally originate in the tropical areas of northern Australia and reach the lake after several months of travel time [16], carrying with them large amounts of water and sediments. During the extensive interflow periods, a thin salt crust covers the lake's sandy soil, under which the soil is often close to saturation at the surface, even during high-temperature summer periods. Because of these environmental conditions, the microwave response from Lake Eyre is expected to be representative of a spatially homogeneous highly saline water saturated area because of the high ground water, with temporal variability caused by thermal cooling and warming of the soil surface layer.

Direct access to Lake Eyre is only possible via a public road to the southwest of the lake. Entering the lake proper, it was found that the ground water level was just below the surface as expected. Installation of the profile soil moisture and temperature sensors was done $\sim 2 \mathrm{~km}$ from the shore into the lake, but all ground-based soil moisture instruments suffered from the high level of salinity in the soil with measurements outside of the physical range. Therefore, quantitative analysis relies on a number of core samples to determine the soil moisture content.

\section{B. Wirrangula Hill}

The area around Wirrangula Hill forms a large plain west of Lake Eyre and northeast of Coober Pedy (Fig. 1; $28.1^{\circ}-28.7^{\circ} \mathrm{S}$ and $\left.135.0^{\circ}-135.8^{\circ} \mathrm{E}\right)$ with its highest elevation in the southwest $(\sim 120 \mathrm{~m})$ and lowest elevation in the northeast $(\sim 80 \mathrm{~m})$. The area is slightly undulating, with no sharp rises in the study area. The majority of the area is covered by a surface rock pavement over sandy clay soil. The surface rock (called gibber) covers the soil in its entirety in most places, with rock diameters ranging from 15 to $200 \mathrm{~mm}$. The larger sized rocks are generally found toward the southern part of the area. An ephemeral stream crosses the area in the northwest containing the only (sparse) woody vegetation of the region. The herbaceous vegetation consists of sparse grasslands, which are often bare, because of the limited precipitation events in this part of Australia. When occurring, those events are generally large-scale systems, evenly depositing the precipitation across the study site. The annual average precipitation is in the order of $100 \mathrm{~mm}$, with the ten-month period between the two experiments only receiving $5 \mathrm{~mm}$. The soil consists predominantly of a compacted clay loam (on average, $18 \%$ sand and $35 \%$ clay). The annual average 
temperature across the field site is $\sim 29{ }^{\circ} \mathrm{C}$ with the lowest daily mean temperature of $19{ }^{\circ} \mathrm{C}$ in July and a maximum of $38{ }^{\circ} \mathrm{C}$ in January. Because of the amount of surface rock cover and the generally homogeneous precipitation events, the microwave response is expected to be homogeneous, as spatial effects caused by soil moisture and/or soil type variability should be reduced.

\section{Simpson Desert}

The Simpson Desert is located $150 \mathrm{~km}$ north of Lake Eyre with the field site found between $26.0^{\circ}-26.7^{\circ} \mathrm{S}$ and $136.7^{\circ}$ $137.3^{\circ} \mathrm{E}$ (Fig. 1). It is a typical sandy desert with the southern area having a more compact surface soil than the northern part. The dunes are generally oriented north-south, spaced anywhere up to $400 \mathrm{~m}$ apart and reaching heights of 10-20 m. The vegetation consists mainly of shrubs (mostly spinnefex) grouped in small patches of up to $2 \mathrm{~m}$ in diameter, and a negligible amount of small woody vegetation. The annual average precipitation is in the order of $60 \mathrm{~mm}$. The soil consists predominantly of sand (on average $73 \%$ sand and $7 \%$ clay). The annual average temperature across the field site is $\sim 30{ }^{\circ} \mathrm{C}$ with the lowest daily mean temperature of $21{ }^{\circ} \mathrm{C}$ in July and a maximum of $41^{\circ} \mathrm{C}$ in January, with daily temperature extremes exceeding $50{ }^{\circ} \mathrm{C}$ at times. Although the microroughness of the surface is very low, it is expected that the large-scale roughness may have a significant impact on the brightness temperature response because of natural erosion processes around the vegetation and the size of the dunes, which result in an increased surface area. Any variability in the microwave emission across the Simpson Desert is expected to be due to the varying surface soil composition (windblown sand on the crests of the dunes and sandy loams in the valley) and the geometry of the dunes (because of a high incidence angle variation and increased surface area). Weather systems are infrequent and generally derived from synoptic events, hence are not expected to influence the spatial variability. In addition, the sparse dry vegetation should have a negligible effect at the spatial resolutions of interest.

\section{Instrumentation}

1) Airborne Instruments: The airborne instruments operated during the two field campaigns include the PLMR [17] and broadband TIR sensors. PLMR consists of a passive microwave antenna array operating at $1.413 \mathrm{GHz}$ with a bandwidth of $25 \mathrm{MHz}$. It includes six beams with view angles of $\pm 7.0^{\circ}, \pm 21.5^{\circ}$, and $\pm 38.5^{\circ}$ from nadir, constantly measuring the surface emissions at alternating $\mathrm{V}$ and $\mathrm{H}$ polarizations. The field of view (FOV) of each beam is $\sim 15^{\circ}$. The broadband TIR instrument covers the $8-14-\mu \mathrm{m}$ band, and is purposebuilt to operate with the same view angles from nadir and the same FOV as PLMR, resulting in identical footprints for both instruments. During the two field campaigns, the aircraft was flown at altitudes of 150 and $3000 \mathrm{~m}$ above ground level with the instruments mounted in a push-broom configuration, resulting in a swath of six pixels across track having resolutions of $\sim 50$ and $1000 \mathrm{~m}$, for the two different flight altitudes, as outlined above.

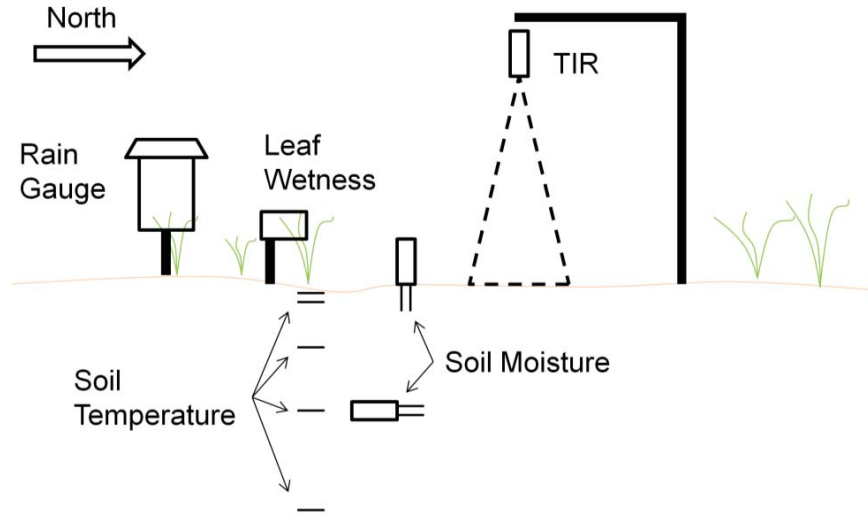

Fig. 2. Schematic representation of the ground station layout (not to scale), with TIR $(2 \mathrm{~m})$, soil temperature $(2.5,5,15,25$, and $40 \mathrm{~cm})$, soil moisture $(0-6$ and at $25 \mathrm{~cm})$, and leaf wetness $(10 \mathrm{~cm})$ sensors.

2) Ground-Based Instruments: The ground-based instrumentation included base stations to continuously monitor the soil profile and handheld soil moisture measuring equipment to observe the spatial surface soil moisture variation across local scales. The ground stations (Fig. 2) consisted of two soil moisture sensors (Delta-T Devices Thetaprobes), five soil temperature sensors (Campbell Scientific T107), a tipping bucket rain gage, dew sensor (Measurement Engineering, Australia LW), and a TIR sensor (Raytek Thermalert). Although the soil moisture measurements were taken vertically at 0-6 $\mathrm{cm}$ and horizontally at $25 \mathrm{~cm}$, the temperature sensors were installed horizontally at $2.5,5,15,25$, and $40 \mathrm{~cm}$. The above-ground instruments were installed at heights of $10 \mathrm{~cm}$ (dew sensor), $50 \mathrm{~cm}$ (rain gage), and $2 \mathrm{~m}$ (TIR). Apart from the rain gage, all the instruments are set to measure every $2 \mathrm{~min}$ and store an average of those values every $20 \mathrm{~min}$. The data from the tipping bucket rain gage are set to record the cumulative rainfall over the same 20 -min period. Finally, volumetric soil samples and surface roughness measurements were collected near the temporary monitoring stations for instrument calibration and surface characterization purposes, along with deep soil core samples in the Simpson Desert and at Wirrangula Hill (only during the first campaign) for the purpose of deep soil temperature and moisture profiles. The roughness measurements were undertaken along two intersecting 2-m long transects in east-west and north-south orientations.

To study the spatial variability of the temperature profiles throughout Wirrangula Hill, five (rather than one) ground stations were installed during the second campaign in August 2009 at different locations. These included the location of the first campaign, with the additional sites located in the vegetation belt of the ephemeral stream in the northwest, the center of the area, and two sites in the south (Fig. 1). Soil moisture and temperature sensors were installed at all sites, with the ground-based TIR located at the central site only.

The handheld equipment to monitor the surface soil moisture across local scales is the HDAS, developed for spatial soil moisture data collection during the National Airborne Field Experiments undertaken in 2005 [17] and 2006 [18]. 
It consists of a Stevens Water Hydraprobe attached to a pole and connected to a GPS enabled hand-held computer running a GIS software to navigate and store the measurement locations, Hydraprobe measurements, and ancillary data. The calibration is undertaken with the extensive data sets collected during the campaigns. A more detailed description of the HDAS and its calibration can be obtained from [15]. The HDAS measurements were taken every $50 \mathrm{~m}$ along the two inner PLMR beam locations for high-resolution flight lines. Measurements were made over a transect length of up to $2 \mathrm{~km}$. Three measurements were taken at each point to reduce observational errors with an expected observation error of $0.03 \mathrm{~m}^{3} \mathrm{~m}^{-3}$ [15].

3) Satellite Data: The SMOS data used in the last section of this analysis are the Level 1c projected and gridded brightness temperatures (version 3.46). The brightness temperatures are corrected for the Faraday rotation effects and transferred from the top of the atmosphere to the ground level rotation. The data are also filtered to include only observations within an incidence range of $\pm 2^{\circ}$ from $38^{\circ}$ to coincide with the PLMR data, and all data outside of the alias-free zone are excluded. All remaining SMOS data falling within this selection are linearly aggregated to obtain an average value.

\section{Methodology}

The brightness temperature data presented in the following sections are corrected to a reference effective soil temperature observed at $6 \mathrm{A.M}$. at the base station following the parameterization of [19], and to a reference incidence angle of $38^{\circ}$ using a methodology similar to [20]. The correction for diurnal changes in the effective soil temperature uses the 6 A.M. soil temperatures observed at 2.5 and $40 \mathrm{~cm}$ at the local ground station to calculate a reference effective temperature, and the ratio between the effective temperature at 6 A.M. to that at other times (in kelvin) as a scaling factor. The angular correction assumes a spatially constant ratio between the brightness temperature means of the different beams. Therefore, the multiplication of the observation at any one location with this ratio transfers the mean of the brightness temperature of the original beam to that of the reference beam. Additionally, the brightness temperature data are filtered to remove the data associated with an aircraft roll of $>2.5^{\circ}$ before the above processing to remove effects of turns and excessive rolling of the aircraft. The data are then binned onto a regular grid with a resolution of $1 \mathrm{~km}$ and averaging all available observations within each $1-\mathrm{km}$ pixel. Similarly, the airborne TIR data are corrected for diurnal variation and outliers in the data, though the temperature correction is done using the ground-based TIR measurements rather than an effective temperature.

\section{Results}

\section{A. Lake Eyre}

The hypothesis for Lake Eyre is that it represents a flat, smooth, wet target, covered by a homogeneous salt crust, with a generally midrange brightness temperature response. The northern part of Lake Eyre peninsula is included in the

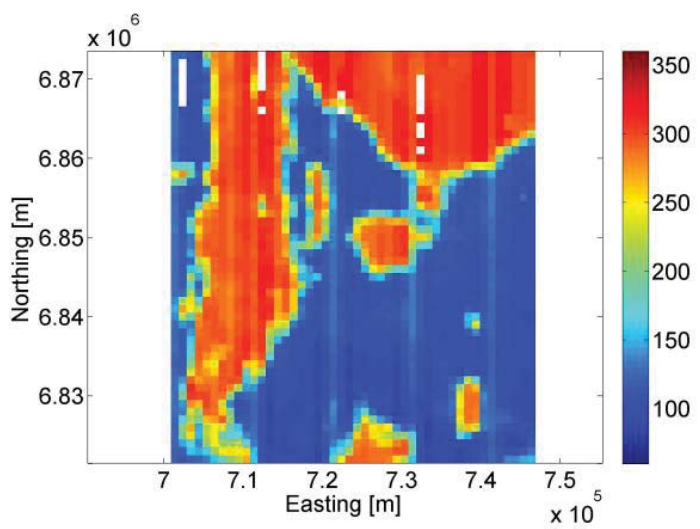

(a)

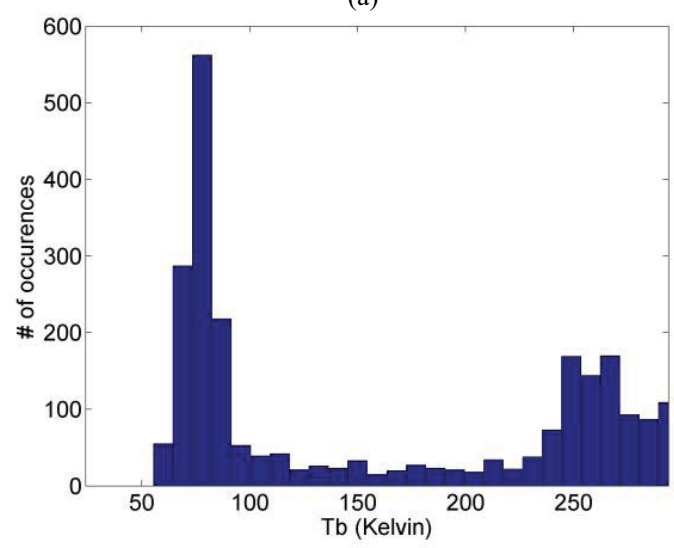

(b)

Fig. 3. (a) Map and (b) histogram of the spatial variability in the brightness temperature (horizontal polarization) across Lake Eyre on November 10, 2008. Gaps are data points removed because of excessive aircraft roll.

southern part of the study area to provide a land contrast and dry reference. Although the roughness and soil moisture measurements support the smooth and wet surface assumption [root mean square (RMS) roughness of $1.35 \mathrm{~mm}$ and saturated soil moisture conditions], the brightness temperature data show unexpected results [Fig. 3(a)].

The data suggest that the surface conditions of Lake Eyre are characterized according to two main types of response, with brightness temperatures similar to: 1) those over dry soil and 2) a very low brightness temperature response akin to very wet and saline conditions. In addition, the variability of the brightness temperature response across this low brightness temperature area is $\sim 13 \mathrm{~K}$. Therefore, despite the wet part of Lake Eyre hypothesized as a potential SMOS calibration target turning out to be much smaller than a SMOS pixel, the spatial variability of this area is also much higher than expected, and too high for vicarious calibration purposes.

The reason for the two distinct responses from Lake Eyre is not entirely clear, as access to most parts of Lake Eyre is impossible without the use of a helicopter. However, the high brightness temperatures in the western and northern parts of the study region coincide with the areas receiving flood waters from the Warburton and Cooper Creeks, and the Diamantina River. The elongated radiometrically warm spatial structure in the north and west of Fig. 3(a) is the Warburton Groove, which receives the first flood waters when any arrive. 

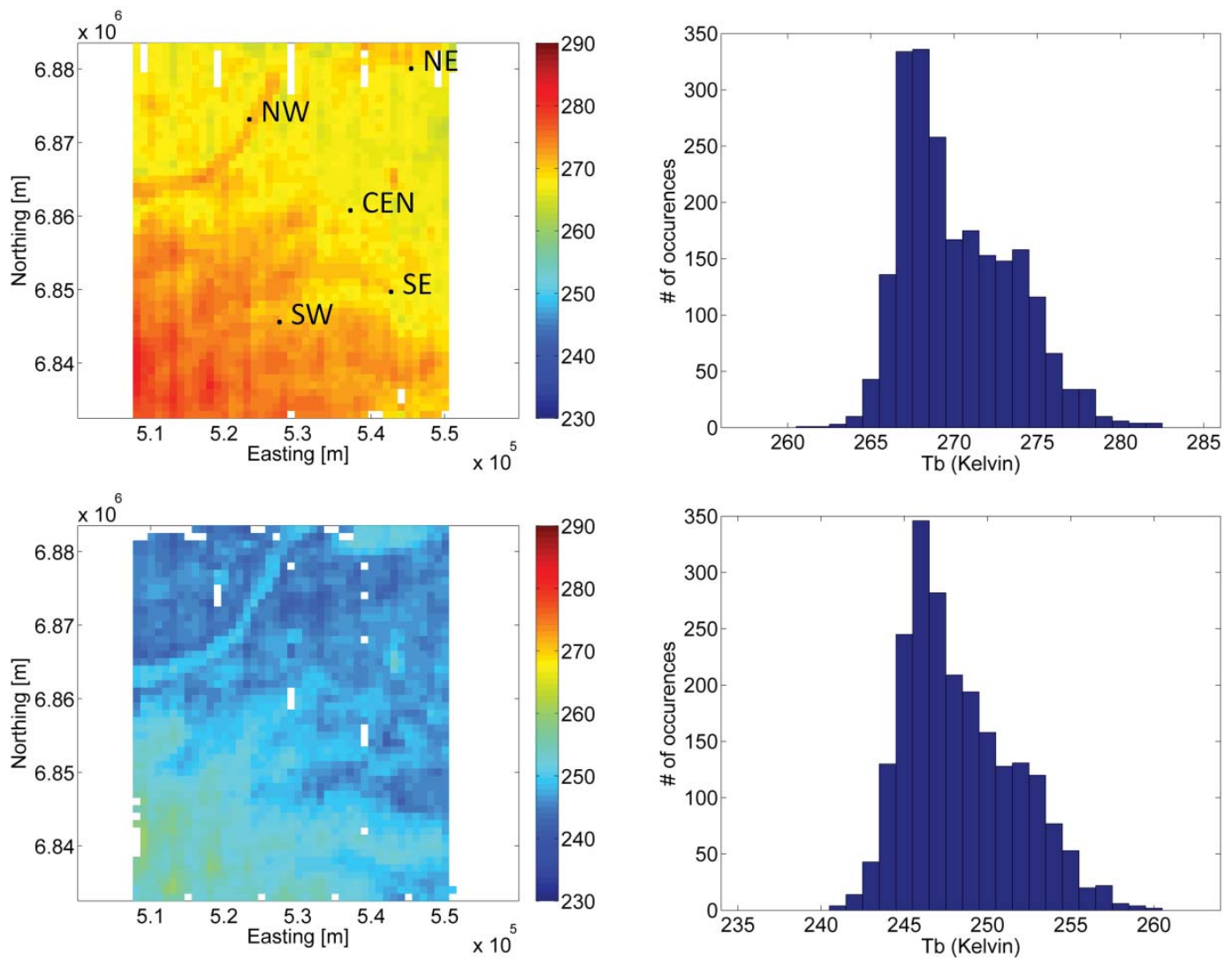

Fig. 4. Spatial maps (including the locations of the temporary monitoring stations) and histograms of the spatial variability in the brightness temperature (horizontal polarization) across Wirrangula Hill on November 12, 2008 (top) and August 12, 2009 (bottom). Gaps are data points removed because of excessive aircraft roll.

Upon entering Lake Eyre, sediments are carried with the flood waters and are deposited in this area, whereas the remaining flood waters continue to flow south. Finally, the warmer areas correspond with higher elevation than the surrounding lake surfaces, suggesting that they are also above the groundwater level. These differences in the surface soil constituency explain the contrast in brightness temperature response, with dry silt deposits in the north and moist hyper-saline conditions with a salt crust in the south.

\section{B. Wirrangula Hill}

For both campaigns, the brightness temperature data obtained over the gibber areas of Wirrangula Hill display a low spatial variability (standard deviation) in their response (3.3 and $3.5 \mathrm{~K}$, respectively; Fig. 4), which is almost identical to that observed during the reconnaissance flight $(4.1 \mathrm{~K})$. Such low spatial variability suggests that a single in situ measurement could be used to estimate the SMOS pixel response within the requirements for a SMOS cal/val site, being equivalent to the $4-\mathrm{K}$ design accuracy [2]. A small gradient in the brightness temperature and airborne TIR is observed with slightly warmer conditions in the southwest. A number of reasons may contribute to this gradient, but most likely is the fact that the surface soil in the south-west was drier than in the north-east $\left(0.02\right.$ and $0.08 \mathrm{~m}^{3} \mathrm{~m}^{-3}$, respectively, during both campaigns). Although it is possible that the rain event passing through the area to the north of the study site before November 8, 2008 may have contributed to this gradient, the same gradient was observed in the August 2009 data [Fig. 4(c)] making this unlikely. It is important to note that the brightness temperature patterns over this field site are essentially the same for measurements made 10 months apart, suggesting that this pattern is persistent. If this is indeed the case, temporal evolution of the brightness temperature can be estimated using a limited number of in situ stations measuring soil moisture and soil temperature, providing that these data can be used to accurately predict the soil's microwave response.

Fig. 5 shows the soil temperature evolution for the observations taken at 2.5 and $40 \mathrm{~cm}$, respectively, at the five stations used during the second campaign. These data support the airborne observations, with soil temperatures at $2.5 \mathrm{~cm}$ being consistently $5-10 \mathrm{~K}$ higher in the south than in the north, apart from during the night time where all the stations are very similar. Overall, the soil temperatures observed at $40 \mathrm{~cm}$ are, with the exception of the north-western site, all within $2 \mathrm{~K}$ of each other at any time. With the airborne observations showing the same spatial patterns for both campaigns, it is expected that the spatial variation in soil temperature throughout the area is typically temporally consistent, and therefore the spatial variation in brightness temperature in the PLMR data may be mostly attributed to the soil temperature gradient. The remainder of the gradient is likely to be caused by the slight soil moisture gradient and the change in surface conditions 

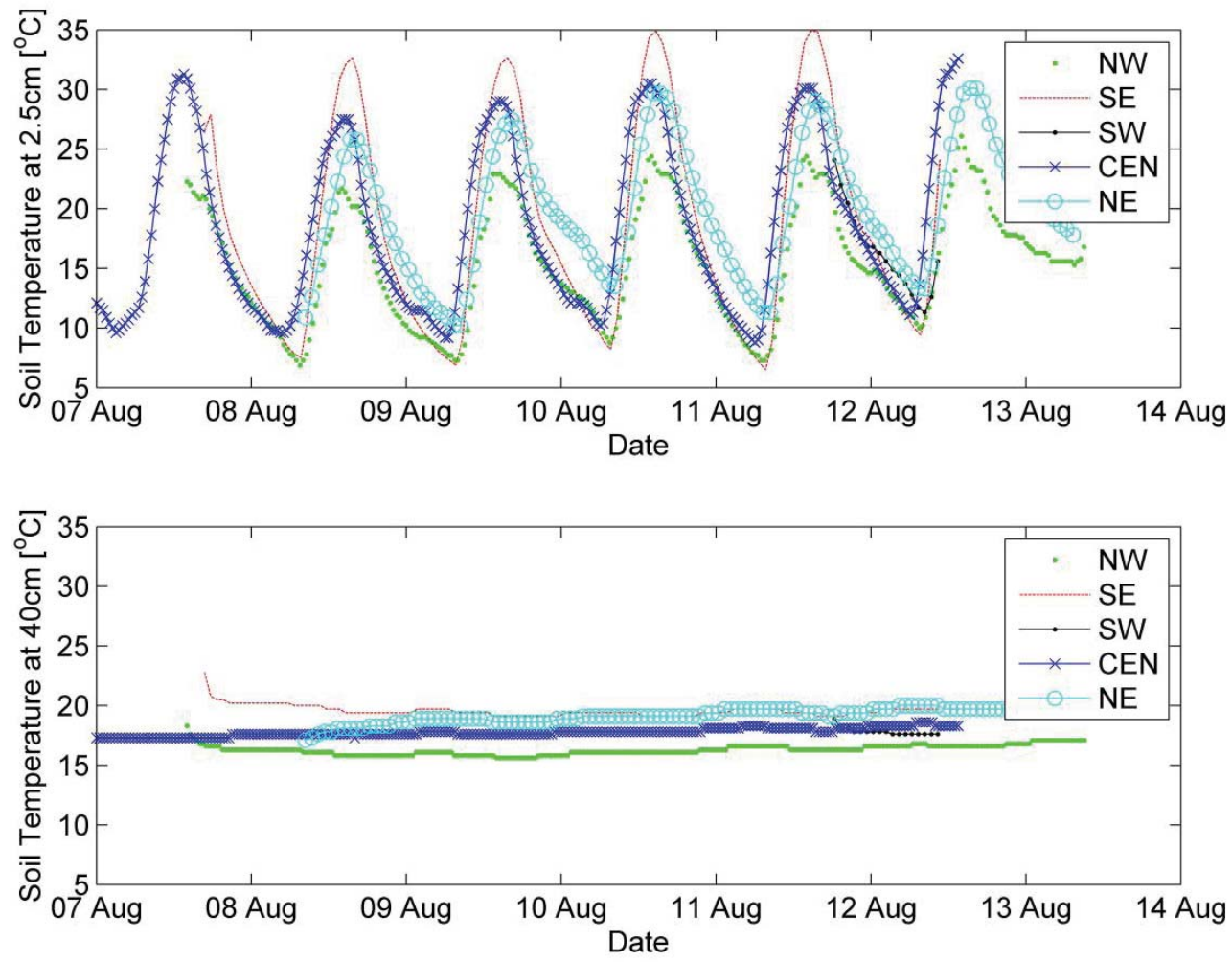

Fig. 5. Surface $(2.5 \mathrm{~cm})$ and deep $(40 \mathrm{~cm})$ soil temperatures as observed at the five monitoring stations in August 2009.

from very loose and almost powdery (southwest) to more compacted conditions (northeast).

\section{Simpson Desert}

A significant rain event passed through the region during the November 2008 campaign. This frontal system deposited several millimeters of rain across the north-eastern part of the focus area in the Simpson Desert in the early morning of November 15, 2008 (the closest weather station at a distance of $\sim 170 \mathrm{~km}$ indicates $7 \mathrm{~mm}$ ). Therefore, the brightness temperature response is found to be bimodal with a significant spatial variability (Fig. 6). For the purpose of testing the hypothesis of a spatially homogeneous brightness temperature response under dry conditions, it is assumed no rainfall occurred in the south-western part of the study site that indicates a dry response, by dividing the area into two parts [black line: Fig. 6(a)]. However, the variability in brightness temperature for this area is still $9.5 \mathrm{~K}$, being substantially higher than that obtained for Wirrangula Hill, and well beyond the SMOS target requirement of $4 \mathrm{~K}$. Although this might suggest there is some lighter rainfall across this area, the amount of spatial variability is consistent with the standard deviation from the reconnaissance flight before the rainfall event $(10.1 \mathrm{~K})$, suggesting that the southern area is not affected by this rain event. However, there may still have been some residual effects from an earlier rain event on November 8, 2008, which deposited $\sim 15 \mathrm{~mm}$ at the nearest rainfall station. In contrast to the flights undertaken in 2008, the repeat flight coverage on August 11, 2009 displays a standard deviation across the entire region of $\sim 1 \mathrm{~K}$ [Fig. 6(c) and (d)], which affirms the initially expected conditions, and suggests that the Simpson Desert may be suitable for vicarious calibrations providing the wetting history is understood and accounted for, on the basis of its low spatial variability.

\section{BRIGHTNESS TEMPERATURE Estimation}

\section{A. Airborne Campaign}

For the calibration of space-borne passive microwave sensors from vicarious ground targets, it is necessary to be able to have an accurate value for the microwave emission. Given that these targets will have a temporally variable emission in response to temporal variation in physical temperature, it is necessary to be able to model the land surface emissions using physically based microwave emission models. Therefore, brightness temperatures are estimated for the Simpson Desert and Wirrangula Hill sites, using the in situ data collected at the ground stations. This is not done for the Lake Eyre site, because it is already being excluded as a potential calibration site on the basis of its size and brightness temperature variation of $13 \mathrm{~K}$ in the wet portion. Similarly, the rain event coincident with the first field campaign over the Simpson Desert means that no coinciding in situ data are collected, and therefore no modeling is conducted for that first campaign. Modeling of brightness temperatures for the two Wirrangula Hill campaigns and the second Simpson Desert campaign is undertaken using the ground station data and the default parameters of the operational radiative transfer model L-band Microwave Emission Model of the Biosphere (L-MEB) [21] (see Table II). Predictions are then compared with PLMR observations as 


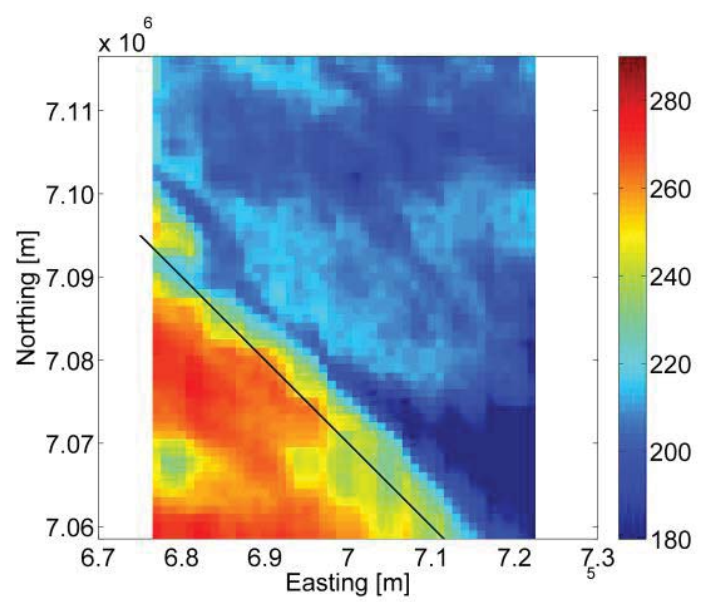

(a)

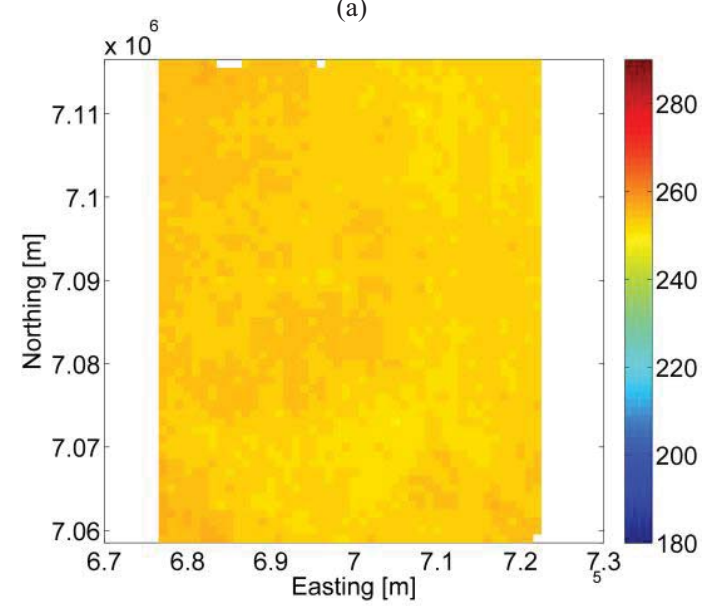

(c)

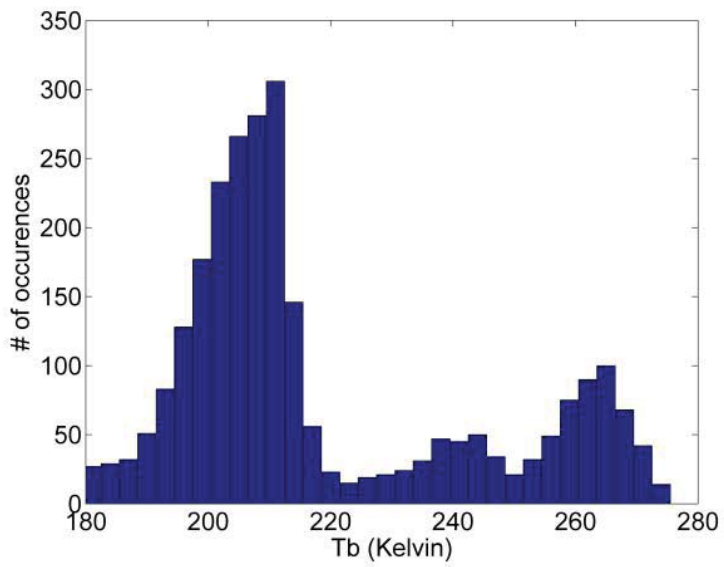

(b)

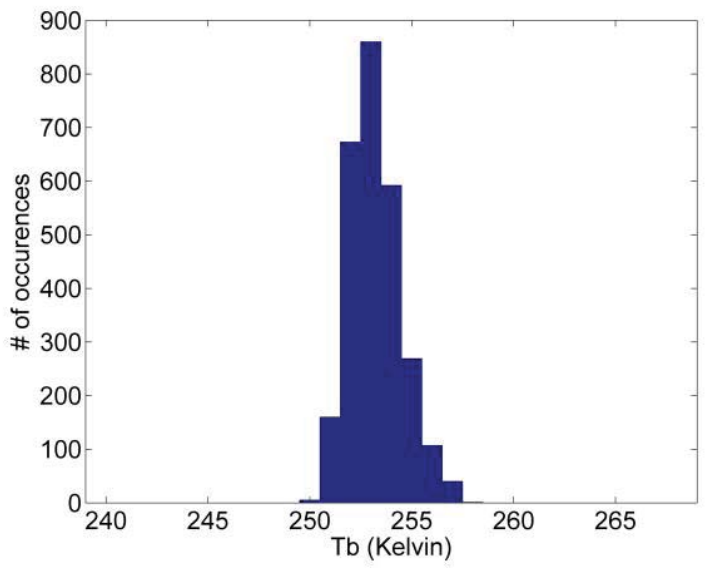

(d)

Fig. 6. (a)-(d) Maps and histograms of the spatial variability in the brightness temperature (horizontal polarization) across the Simpson Desert on November 15, 2008 (top row) and August 11, 2009 (bottom row).

TABLE II

Soil AND STANDARd Model Parameters of L-MEB [21] USED For THE FORWARD MODELING OF THE BRIGHTNESS TEMPERATURES Over WirRangula Hill and the Simpson Desert

\begin{tabular}{|l|c|c|}
\hline Parameter & Wirrangula Hill & Simpson Desert \\
\hline Sand $(\%)$ & 18 & 73 \\
\hline Clay $(\%)$ & 35 & 7 \\
\hline Density $\left(\mathrm{g} \mathrm{cm}^{-3}\right)$ & 1.3 & 1.5 \\
\hline$\tau$ & 0 \\
\hline tth & 1 \\
\hline $\mathrm{rtt}$ & 1 \\
\hline$\omega v \& \omega h$ & 0 \\
\hline$H_{R}$ & $0.2(0.5)$ \\
\hline$N_{R v}$ & -1 \\
\hline$N_{R h}$ & 0 \\
\hline$Q_{R}$ & 0 \\
\hline$\theta\left[\mathrm{m}^{3} \mathrm{~m}^{-3}\right]$ & 0.06 \\
\hline
\end{tabular}

a demonstration of the ability to use ground soil moisture and temperature measurements in these locations to calibrate SMOS.

The brightness temperature forward simulations for Wirrangula Hill results in values with a deviation from the mean of the airborne brightness temperatures of $2.3 \mathrm{~K}$ for both campaigns. This suggests that Wirrangula Hill is a very good candidate for L-band passive microwave satellite calibration efforts. In contrast, the simulations for the Simpson Desert show a bias of $15 \mathrm{~K}$ in vertical and $20 \mathrm{~K}$ in horizontal polarization model estimates as compared with observations. On the basis of a single snapshot in time, this bias cannot be explained. However, it suggests a lack of understanding in the underlying physics that are occurring in this location, or in the physical representation of those conditions within the dielectric constant model used within the radiative transfer model.

Calibration errors of PLMR may be discarded as a significant source because of the 2-K accuracy achieved with the cold (sky) and warm (control reference) calibration procedure undertaken for each flight [17]. One unaccounted effect may be the increased surface area of the desert because of the dunes, increasing the microwave emission, but assuming a 200-m dune spacing and an average height of $15 \mathrm{~m}$ increases the surface area by only $2 \%$ (or $\sim 5-7 \mathrm{~K}$ ). Other possible explanations include increased volume scattering in the dry soil and larger effects of the warmer (in the early morning) deeper soil layers, as the level of compaction increases with 


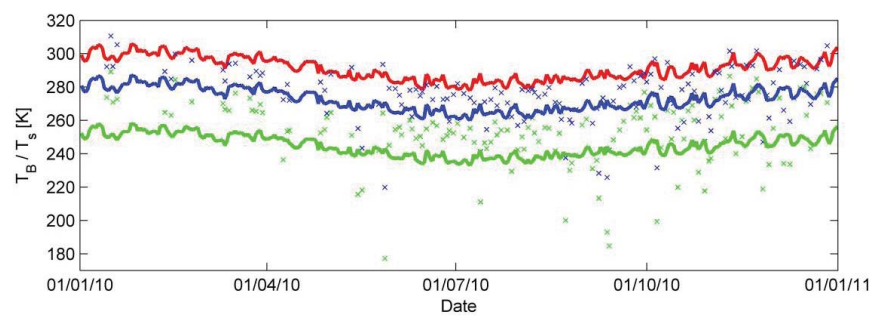

Fig. 7. Vertically (blue crosses) and horizontally (green crosses) polarized SMOS level 1c brightness temperatures observed in 2010 over the Wirrangula Hill field site, together with forward modeled values (lines; polarizations in the same colors as the crosses) using the ERA-Interim soil temperature predictions (red line) and a constant soil moisture content of $0.06 \mathrm{~m}^{3} \mathrm{~m}^{-3}$.

depth. Although dunes have a dominant orientation, i.e., one side is steeper than its counterpart because of dominant wind directions, a bias in the incidence angle is not expected to be the reason for the bias in the brightness temperature data, as it would have opposing effects in the horizontally (decreasing $\mathrm{Tb}$ ) and vertically (increasing $\mathrm{Tb}$ ) polarized observations. However, in both cases, the model underestimates the observations by a similar amount. Without an improvement of the radiative transfer model for the prevailing conditions in sandy desert areas, it will remain difficult to accurately model the microwave emission from this area. Therefore, the Simpson Desert cannot be recommended as a vicarious calibration site for passive microwave satellite missions. Thus, either the models need to be improved to account for unique conditions of the Simpson Desert, or the persistency of this difference understood, if the Simpson Desert is to be used as a vicarious calibration target. Therefore, the Simpson Desert is not considered further as a suitable vicarious target in this paper.

\section{B. Satellite}

The above results are for two instants in time only, therefore, a further study covering an extensive time is required to verify that the data collected on those two days are representative of typical conditions. Therefore, SMOS Level 1c brightness temperatures are compared with L-MEB predictions using soil temperature data from ECMWF ERA-Interim [22]. To facilitate the comparison with PLMR data and to be consistent with earlier figures, only averaged SMOS data from $38 \pm 2^{\circ}$ incidence angle observations are shown. Fig. 7 shows the observed and modeled brightness temperatures for Wirrangula Hill, with model predictions based on the same standard L-MEB parameterization used in the PLMR comparison. For simplicity and to avoid further assumptions that could introduce more uncertainties, the effective soil temperature is taken to be the surface layer temperature of the model output and the soil moisture is assumed a constant $0.06 \mathrm{~m}^{3} \mathrm{~m}^{-3}$. Subsequently, SMOS is found to be warmer in comparison with the model predicted brightness temperatures by 4.6 and $11.1 \mathrm{~K}$ (vertical and horizontal polarizations, respectively), excluding rainy periods. However, it is clear that the temporal variation is well matched with a near-constant offset, when smoothing the orbit-to-orbit noise in SMOS brightness temperatures and ignoring precipitation events. When removing the constant bias amount, the RMS difference (RMSD) between the modeled predictions and the SMOS observations reduces to $10 \mathrm{~K}$.

It is important to note that while these differences may be in part because of the assumptions of constant soil moisture and a modeled soil temperature, the temporal evolution of the brightness temperature emissions is well reproduced. The ERA-Interim soil temperatures, as well as the observed brightness temperature data show an intra-annual variability of $20 \mathrm{~K}$. Given that both brightness and physical temperatures track this temporal variation gives some confidence in the results and suggests that the temporal evolution of brightness temperature can be predicted from ground observations, with precipitation events having only a short-term influence on the microwave emission. In addition, the rainfall produces radiometrically distinctive events that can be easily filtered out for the purpose of calibration. This suggests that ERA-Interim data may be used as a substitute for the ground observations of soil temperature required to account for the large variability throughout the year, if in situ measurements are not available. In addition, the difference in brightness temperatures may in part be explained by the assumption of a given soil moisture (measured at one point in time) and the ERA-Interim soil temperatures, e.g., a wet bias in the representation of soil moisture within the land surface model would result in lower physical temperatures of the soil and lead to potential biases in the L-MEB predictions. This has to be further investigated, but will require long-term in situ soil moisture and temperature observations for the validation of the model.

\section{CONCLUSION}

This paper explored the suitability of three sites within the Australian arid zone that were hypothesized to be appropriate vicarious calibration sites for space-borne passive microwave instruments at L-band. The assumptions for those sites were that the microwave response would be spatially uniform and temporally predictable, because of their homogeneous surface conditions (sandy desert, gibber, and dry salt lake). The sites were visited on two occasions, under different environmental conditions.

It was shown that Lake Eyre had a cool target response for only a portion of the lake, being much smaller than a SMOS footprint. In addition, even this cool target area had a spatial variability of $15-20 \mathrm{~K}$ that is much greater than the requirement for calibration purposes. Although the Simpson Desert was initially found to have a spatial variability of $\sim 10 \mathrm{~K}$, the second campaign showed a spatial variability of only $1 \mathrm{~K}$. This means that the Simpson Desert could make an ideal calibration target under the right conditions; i.e., after a long sustained period of dry weather. However, there was a discrepancy between modeled and observed brightness temperature that needs to be resolved before a calibration procedure relying on in situ point measurements can be implemented for this site. In addition, there are logistical difficulties with installing and maintaining monitoring stations in this area, meaning that it is best suited to vicarious calibration through coincident airborne coverage of the area. However, the more easily accessed gibber site of Wirrangula Hill showed 
potential as a vicarious calibration site. It was found to have a $\sim 4-\mathrm{K}$ spatial variability for all flights, which was within the design calibration accuracy of SMOS. In addition, model predictions of brightness temperature from Wirrangula Hill in situ monitoring data agreed with coincident aircraft data to within 5-10 K. Comparison of SMOS observations and model predicted brightness temperatures for the Wirrangula Hill site also showed a good temporal coherence, but with a warm bias in SMOS of $5 \mathrm{~K}$ at vertical polarization and $11 \mathrm{~K}$ at horizontal polarization, when using model rather than in situ soil moisture and temperature data. In addition, when removing this bias, the RMSD between SMOS observations and model predictions was $\sim 10 \mathrm{~K}$ for both polarizations.

This persistent difference between model predictions and SMOS observations suggests some limitations either in the observations or the model. As the same differences were seen in the higher resolution airborne data, it was concluded that the majority of the error lies within the model representation particularly of the Simpson Desert, suggesting a need to improve our understanding of the emission from a sandy desert area. In this paper, version 3.46 of the SMOS soil moisture product was used. The change of the dielectric constant model within the radiative transfer model may show a better correspondence. However, this assessment will be discussed in a future study.

\section{ACKNOWLEDGMENT}

The authors would like to thank the invaluable field work assistance, in particular of A. Marks and J. Johansson, who participated in both campaigns. Other participants of the first campaign were M. Allahmoradi, J. Costelloe, S. Hayes, V. Matic, S. Peischl, P. Richardson, D. Ryu, G. Tomlinson, and N. Ye. Hangar space for the research equipment at the Coober Pedy airport was provided by Opal Air. Some equipment and the main PLMR processing software, as well as a share of their experience in airborne campaigns were provided by Airborne Research Australia, Flinders University. Finally, the authors would like to acknowledge the help of Arnaud Mialon with processing of the SMOS data, as well as Clément Albergel and Gianpaolo Balsamo for providing the ERA-Interim data.

\section{REFERENCES}

[1] Y. Kerr, P. Waldteufel, J. P. Wigneron, J. M. Martinuzzi, J. Font, and M. Berger, "Soil moisture retrieval from space: The Soil Moisture and Ocean Salinity (SMOS) mission," IEEE Trans. Geosci. Remote Sens., vol. 39, no. 8, pp. 1729-1735, Aug. 2001.

[2] Y. Kerr, P. Waldteufel, J. Wigneron, S. Delwart, F. Cabot, J. Boutin, M. Escorihuela, J. Font, N. Reul, and C. Gruhier, "The SMOS mission: New tool for monitoring key elements of the global water cycle," Proc. IEEE, vol. 98, no. 5, pp. 666-687, May 2010.

[3] P. Gloersen and F. T. Barath, "A scanning multichannel microwave radiometer for Nimbus-G and SeaSat-A," IEEE J. Ocean. Eng., vol. 2, no. 2, pp. 172-178, Apr. 1977.

[4] E. G. Njoku, T. J. Jackson, V. Lakshmi, T. K. Chan, and S. V. Nghiem, "Soil moisture retrieval from AMSR-E," IEEE Trans. Geosci. Remote Sens., vol. 41, no. 2, pp. 215-229, Feb. 2003.
[5] P. W. Gaiser, K. M. St Germain, E. M. Twarog, G. A. Poe, W. Purdy, D. Richardson, W. Grossman, W. L. Jones, D. Spencer, G. Golba, J. Cleveland, L. Choy, R. M. Bevilacqua, and P. S. Chang, "The WindSat spaceborne polarimetric microwave radiometer: Sensor description and early orbit performance," IEEE Trans. Geosci. Remote Sens., vol. 42, no. 11, pp. 2347-2361, Nov. 2004.

[6] T. Kawanishi, T. Sezai, Y. Ito, K. Imaoka, T. Takeshima, Y. Ishido, A. Shibata, M. Miura, H. Inahata, and R. Spencer, "The Advanced Microwave Scanning Radiometer for the Earth Observing System (AMSR-E), NASDA's contribution to the EOS for global energy and water cycle studies," IEEE Trans. Geosci. Remote Sens., vol. 41, no. 2, pp. 184-194, Feb. 2003.

[7] E. Njoku, T. Chan, W. Crosson, and A. Limaye, "Evaluation of the AMSR-E data calibration over land," Ital. J. Remote Sens., vol. 30, pp. 19-37, Apr. 2004.

[8] Y. Kerr, P. Waldteufel, P. Richaume, I. Davenport, P. Ferrazzoli, and J. Wigneron, "SMOS level 2 Processor for Soil Moisture Algorithm Theoretical Based Document (ATBD)," SM-ESL (CBSA), CESBIO, Toulouse, Tech. Rep. SO-TN-ESL-SM-GS-0001, 2010.

[9] D. Levine and S. Abrams, "Galactic noise and passive microwave remote sensing from space at L-band," IEEE Geosci. Remote Sens., vol. 42, no. 1, pp. 119-129, Jan. 2004.

[10] G. Macelloni, M. Brogioni, P. Pampaloni, M. Drinkwater, and A. Cagnati, "DOMEX 2004: An experimental campaign at Dome-C Antarctica for the calibration of space-borne low-frequency microwave radiometers," IEEE Trans. Geosci. Remote Sens., vol. 44, no. 10, pp. 2642-2653, Oct. 2006

[11] D. Burrage, J. Wesson, and J. Miller, "Deriving sea surface salinity and density variations from satellite and aircraft microwave radiometer measurements: Application to coastal plumes using STARRS," IEEE Trans. Geosci. Remote Sens., vol. 46, no. 3, pp. 765-785, Mar. 2008.

[12] S. T. Brown and C. S. Ruf, "Determination of an Amazon hot reference target for the on-orbit calibration of microwave radiometers," J. Atmosph. Ocean. Tech., vol. 22, no. 9, pp. 1340-1352, 2005.

[13] W. Zhang, J. Wu, H. Liu, and H. Liu, "First result from Takelimgan desert campaign for SMOS CAL/VAL," in Proc. IEEE Geosci. Remote Sens. Symp., Jan. 2010, pp. 3797-3800.

[14] Australian Bureau of Meteorology, Australian Government Printing Service, Canberra, Australia, 1988, p. 67.

[15] O. Merlin, J. P. Walker, R. Panciera, R. Young, J. D. Kalma, and E. J. Kim, "Calibration of a soil moisture sensor in heterogeneous terrain with the National Airborne Field Experiment (NAFE) Data," in Proc. Int. Congr. Model. Simul., Dec. 2007, pp. 2604-2610.

[16] V. Kotwicki, "Floods of Lake Eyre, Adelaide," Ph.D. dissertation, Dept. Eng. Water Supply, Univ. Adelaide, Des Moines, LA, USA, 1986.

[17] R. Panciera, J. P. Walker, J. D. Kalma, E. J. Kim, J. Hacker, O. Merlin, and M. Berger, "The NAFE'05/CoSMOS dataset: Toward SMOS soil moisture retrieval, downscaling and assimilation," IEEE Trans. Geosci. Remote Sens., vol. 46, no. 3, pp. 736-745, Mar. 2008.

[18] O. Merlin, J. P. Walker, J. D. Kalma, E. J. Kim, J. Hacker, R. Panciera, R. Young, G. Summerell, J. Hornbuckle, M. Hafeez, and T. Jackson, "The NAFE'06 data set: Toward soil moisture retrieval at intermediate resolution," Adv. Water Resour., vol. 31, no. 11, pp. 1444-1455, Nov. 2008.

[19] J. P. Wigneron, A. Chanzy, P. De Rosnay, C. Rüdiger, and J.-C. Calvet, "Estimating the effective soil temperature at L-band as a function of soil properties," IEEE Trans. Geosci. Remote Sens., vol. 46, no. 3, pp. 797-807, Mar. 2008.

[20] T. J. Jackson, "Multiple resolution analysis of L-band brightness temperature for soil moisture," IEEE Trans. Geosci. Remote Sens., vol. 39, no. 1, pp. 151-164, Jan. 2001.

[21] J.-P. Wigneron, Y. Kerr, P. Waldteufel, K. Saleh, P. Richaume, P. Ferrazzoli, M.-J. Escorihuela, J. P. Grant, B. Hornbuckle, P. de Rosnay, J. C. Calvet, T. Pellarin, R. Gurney, and C. Mätzler, "L-band microwave emission of the biosphere (L-MEB) Model: Description and calibration against experimental data sets over crop fields," Remote Sens. Environ., vol. 107, no. 4, pp. 639-655, Apr. 2007.

[22] D. P. Dee, S. M. Uppala, A. J. Simmons, P. Berrisford, P. Poli, S. Kobayashi et al., "The ERA-Interim reanalysis: Configuration and performance of the data assimilation system," Q. J. R. Meteorol. Soc., vol. 137, no. 656, pp. 553-597, Apr. 2011. 


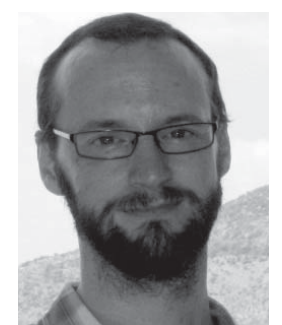

Christoph Rüdiger (M'10) received the Degree in civil engineering (BE) from the University of Applied Sciences, Wiesbaden, Germany, in 2002. His undergraduate thesis covered the topic of groundwater and contaminant flow around future buildings, and the Ph.D. degree in environmental engineering from the University of Melbourne, Parkville, Australia, in 2007, studying the potential to assimilate streamflow data into land surface models for soil moisture prediction.

$\mathrm{He}$ joined the Centre National de Recherches Météorologiques at Météo France, Toulouse, France, to work on the preparation of surface soil moisture and LAI data assimilation into the French land surface model ISBA. During this period, he also worked on the validation of different passive and active microwave satellite products over France, with a particular focus on ESA's SMOS. Since his return to Australia in July 2008, he has coordinated and led a number of cal/val campaigns for the Australian land validation segment of the SMOS mission in the Australian arid zone and the Murrumbidgee River catchment. In addition to this, he continues to work on land surface data assimilation and also participates in the Australian cal/val segments for NASA's SMAP and Aquarius. He is currently a Lecturer with Monash University, Melbourne, Australia. His current research interests include the remote sensing of vegetation dynamics and landscape water content.

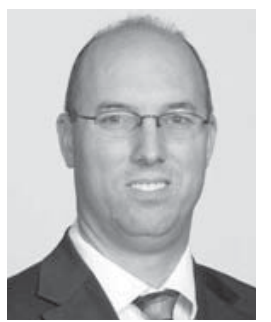

Jeffrey P. Walker received the B.E. degree in civil engineering and B.Surveying degree (Hons. 1 and University Medal) in 1995, and the Ph.D. degree in water resource engineering from the University of Newcastle, Callaghan, Australia, in 1999. His Ph.D. thesis was among the early pioneering research on estimation of root-zone soil moisture from assimilation of remotely sensed surface soil moisture observations.

He joined NASA Goddard Space Flight Center to implement his soil moisture work globally. In 2001, he moved to the Department of Civil and Environmental Engineering, University of Melbourne, Parkville, Australia, as a Lecturer, where he continued his soil moisture work, including development of the only Australian airborne capability for simulating new satellite missions for soil moisture. In 2010, he was appointed as a Professor with the Department of Civil Engineering, Monash University, Melbourne, Australia, where he is continuing this research. He is currently contributing to soil moisture satellite missions at NASA, ESA, and JAXA, as a Science Definition Team member for the Soil Moisture Active Passive (SMAP) mission and Cal/val Team member for the Soil Moisture and Ocean Salinity and Global Change Observation Mission Water respectively.

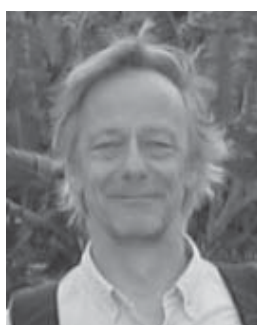

Yann H. Kerr (M'88-SM'01-F'13) received the Engineering degree from Ecole Nationale Supérieure de l'Aéronautique et de l'Espace, the M.Sc. degree in electronics and electrical engineering from Glasgow University, Glasgow, Scotland, and the Ph.D. degree in Astrophysique, Géophysique et Techniques Spatiales, Université Paul Sabatier, Toulouse, France.

He was an EOS Principal Investigator (interdisciplinary investigations) and Principal Investigator and Precursor of the use of the SCAT over land. In 1990, he started to work on the interferometric concept applied to passive microwave earth observation and was subsequently the science lead on the MIRAS project for ESA. In 1997, he proposed the SMOS Mission, the natural outcome of the previous MIRAS work. He is currently involved in the exploitation of SMOS data, in the Cal Val activities and related level 2 soil moisture and level 3 and 4 developments. He is also working on the SMOS next concept and is involved in both the Aquarius and SMAP missions. He is currently the Director of Centre d'Etudes Spatiales de la BIOsphère, Toulouse. His current research interests include the theory and techniques for microwave and thermal infrared remote sensing of the Earth, with emphasis on hydrology and water resource management.

Dr. Kerr was the recipient of the World Meteorological Organization 1st prize (Norbert Gerbier), the USDA Secretary's Team Award for excellence (Salsa Program), the GRSS certificate of recognition for leadership in development of the first synthetic aperture microwave radiometer in space and success of the SMOS mission, and is a Distinguished Lecturer for GRSS.

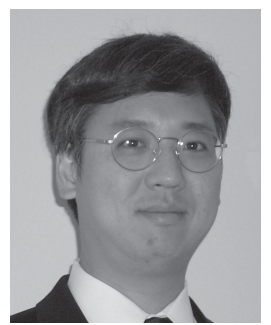

Edward J. Kim (S'90-M'99-SM'05) received the S.B. and S.M. degrees in electrical engineering from the Massachusetts Institute of Technology, Cambridge, MA, USA, and a joint Ph.D. degree from the Departments of Electrical Engineering and Atmospheric Sciences, University of Michigan, Ann Arbor, MI, USA, in 1998.

He has been with NASA's Goddard Space Flight Center, Greenbelt, MD, USA, since 1999, developing and applying techniques for water cycle remotesensing, primarily focused on calibration and validation, and has participated in numerous soil moisture and snow remote sensing field campaigns in Australia and the US. He is responsible for post-launch brightness temperature calibration for NASA's upcoming SMAP soil moisture mission. He serves as NASA's Instrument Scientist for the ATMS microwave sounder on the S-NPP \& JPSS satellites, and serves on the Cal/Val teams for passive microwave sensors from Europe, Japan, and India.

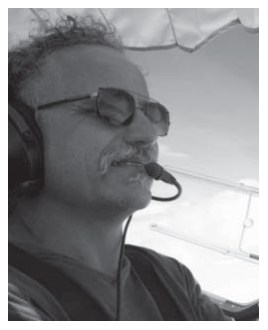

Jörg M. Hacker received the Doctorate (Dr.rer.nat.) degree in atmospheric sciences from the Meteorological Institute of the University of Bonn, Bonn, Germany, in 1980.

He was the Research Fellow with the University of Bonn until 1982. In 1982, he was a PostDoctoral Fellow with the Flinders University of South Australia, Adelaide, South Australia, where from the beginning, he built up Australia's National Research Aircraft Facility ARA - Airborne Research Australia, which today is Australia's only National Facility engaged in using and operating aircraft for atmospheric and environmental research. Currently, he is ARA's Director and Chief Scientist, and also an Associate Professor within Flinders University. He was instrumental in securing one of the very few civilian high-altitude research aircraft (the Grob G520T Egrett which can fly research missions to altitudes as high as $15 \mathrm{~km}$ ) for the facility and is now flying regularly as mission specialist in this aircraft all over the world. His current research interests include wide area, with special emphasis on the atmospheric boundary layer and the development of innovative instrumentation and measurement strategies using airborne platforms. He was co-author of more than 80 publications in internationally refereed journals and more than 150 conference papers. He pioneered the concept of using cost-efficient small aircraft for atmospheric research, including the research described in the current paper. He holds a pilot's license with several special endorsements and has more than 7000 flying hours in a wide range of aircraft, including flying gliders over the Andes in South America up to $12.5 \mathrm{~km}$. In the context of his research, he also regularly flies aircraft as low as $10 \mathrm{~m}$ above the ground.

Dr. Hacker was the recipient of the prestigious Max-Planck-Prize, for his international science activities, in 1994 together with colleagues Professor Helmut Kraus (University of Bonn) and Prof. P. Schwerdtfeger (Flinders University), awarded jointly by the German Alexander-von-Humboldt-Foundation and the Max-Planck-Society. Together with H.W. Grosse, he holds the World Record for flying a self-launching glider over a 500-km triangle at an average speed of $172 \mathrm{~km} / \mathrm{h}$.

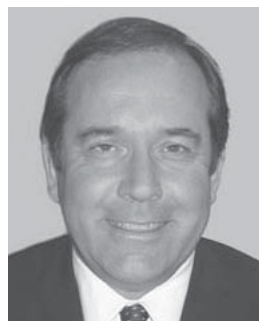

Robert J. Gurney received the Ph.D. degree from the University of Bristol, Bristol, U.K., in 1975.

He was with the Institute of Hydrology, Wallingford, U.K. for five years, at the Hydrological Sciences Branch of the NASA Goddard Space Flight Center for eight years, five as Head, two years with the Department of Civil Engineering, University of Maryland, College Park, MD, USA, five years as Director of the Unit for Thematic Information Systems, Natural Environment Research Council (NERC), Reading, U.K., and from 1995 to 2012, he was the Director of the NERC Environmental Systems Science Centre. He is currently a Professor of earth observation science, Reading University. His current research interests include global environment change. 


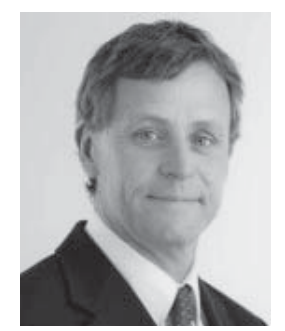

Damian Barrett received the B.Sc. (First Class Hons) form Adelaide University, Adelaide, South Australia, in 1987, and the Ph.D. degree from the Australian National University, Canberra, Australia, in 1993 .

He currently leads the "Water in the Resources Sector" research stream in the Water for a Healthy Country Flagship Program at CSIRO, Australia, and is an Adjunct Professor with the Centre for Water, Minerals Industry, Sustainable Minerals Institute, The University of Queensland, St Lucia, Australia. He has more than 20 years of research experience in CSIRO, Cooperative Research Centre (CRC) for Greenhouse Accounting, eWater CRC and The University of Queensland. In July 2008, he was a Professorial Research Fellow with the Sustainable Minerals Institute, University of Queensland, and was the Director of the Centre for Water in the Minerals Industry from 2009 to 2012. he has worked with the minerals industry, state government and the Minerals Council of Australia on environmental issues associated with water, biodiversity, and the impacts of mining on landscape ecosystem functioning. $\mathrm{He}$ also advised on policy development, strategic water management and environmental science to senior management in global mining companies operating in Australia, Mongolia, Chile, and South Africa. He has authored/coauthored more than 65 research papers in journals, reports, and conference proceedings with over 1100 citations. He has presented at more than 30 national and international workshops and conferences in the last ten years on topics as diverse as water availability forecasting, the global terrestrial carbon cycle and greenhouse mitigation, satellite observation and modelling of water and carbon cycles, human impacts and global change, sustainability, mining and biodiversity, and water issues in the minerals industry.

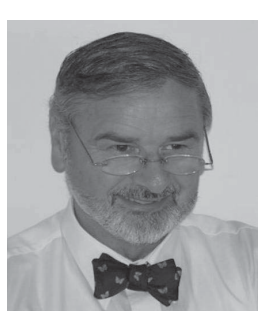

John Le Marshall was Director of the NASA, NOAA, DoD Joint Center for Satellite Data Assimilation from 2003 to 2007, which is responsible for the efficient and timely introduction of new satellite data into the operational weather, climate, and oceanographic forecast systems of the Center's partner agencies, in particular those of the NOAA, including the National Weather Service, NASA's Global Modeling and Assimilation Office and the U.S. Naval Research Laboratory. He returned to the Australian Bureau of Meteorology in 2007, where he works on planning for and implementation of advanced satellite systems and in the remote sensing and data assimilation research area. 